\title{
INVESTIGATION AND ANALYSIS OF TWO COPTIC TEXTILE FRAGMENTS IN THE AGRICULTURAL MUSEUM IN EGYPT
}

\author{
Nabil Mabrouk \\ Damietta University, Egypt \\ nsh00@du.edu.eg
}

\section{ABSTRACT}

The present study addressed important investigation and analytical techniques used in assaying the deterioration phenomena and identifying the components of two degraded Coptic textile fragments preserved in the Agricultural Museum in Egypt. The first fragment dates to the $2^{\text {nd }}-3^{\text {rd }}$ century $A D$, the second one dates to the $5^{\text {th }}-6^{\text {th }}$ century AD. The study used stereo microscope (SM), scanning electron microscopy coupled with energy dispersive $\mathrm{X}$-ray spectroscopy unit (SEM-EDXS), high-performance liquid chromatography coupled with diode array detection and mass spectrometry (HPLCDAD-MS), and Fourier transformer infrared spectroscopy by attenuated total reflection (FTIR-ATR) to examine the objects. The results revealed that the objects were made from natural wool, dyed with natural dyes, namely indigo, madder, and weld, and ornamented with small blank linen threads. The weaving structure is the tapestry technique with a little embroidery lace in the first fragment. The analytical results revealed that the fragments suffered from extensive deterioration, due to dust, soiling matters, stains, holes, missing parts, old adhesive, brittleness, and high acidity.

KEYWORDS

Coptic Textiles, Investigation, Analysis, deterioration, Conservation.

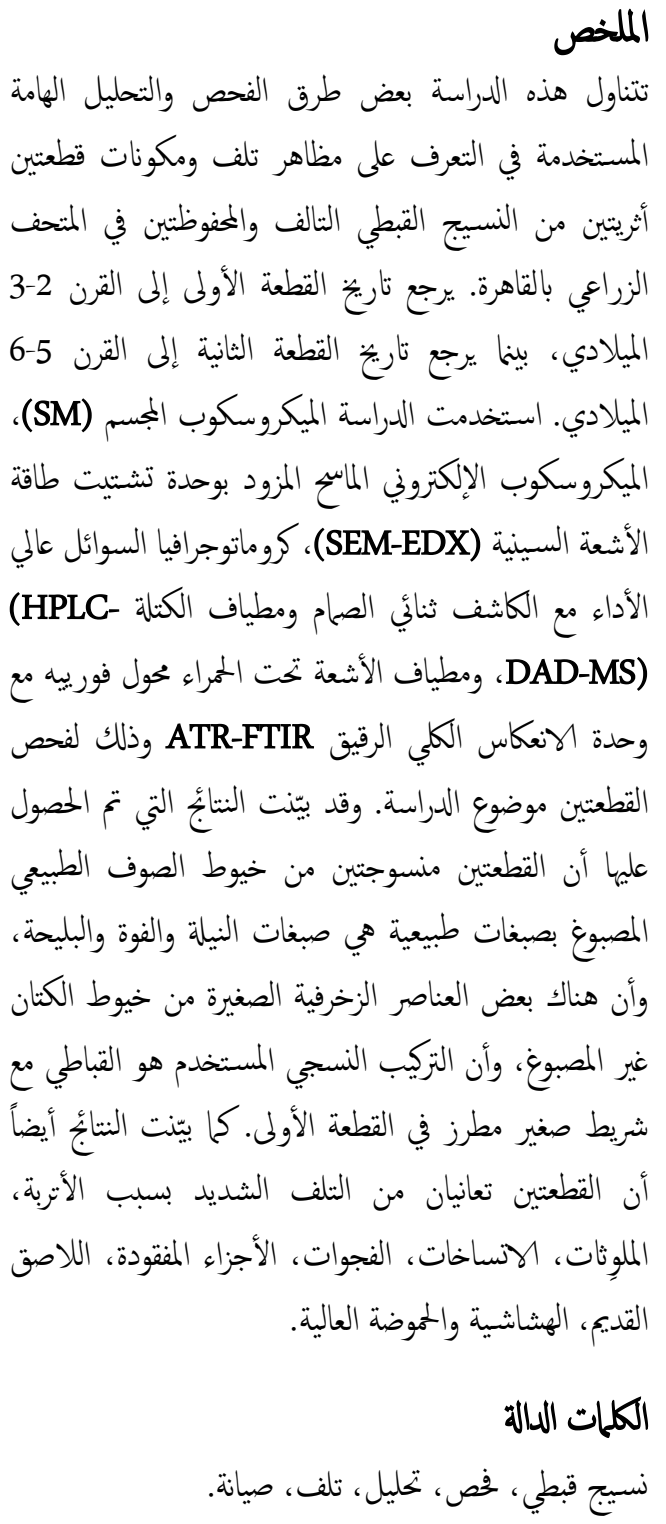




\section{INTRODUCTION}

"Coptic textile" is a term usually applied to a large number of Egyptian polychromatic textiles produced in Egypt from the Roman era to Islamic times. Scholars use different terms to describe these textiles, such as Greco-Roman, Late Antique, Late Roman, and Early Byzantine. ${ }^{1}$ Between the $4^{\text {th }}$ and the $7^{\text {th }}$ centuries AD, Coptic textiles were woven in the plain tapestry technique, using plant fibers, like linen, and/or animal fibers, like wool, dyed with natural dyes from plant and/or animal origins. Later, these plain tapestries were increasingly embroidered and decorated with additional dyed wool or silk threads. ${ }^{2}$ The decorative elements of Coptic textiles generally include symbol animals, plants, and sometimes human elements. ${ }^{3}$

Despite dissimilarity between the Coptic art and the ancient Egyptian art, the Coptic one is based and affected by the ancient Egyptian one, especially in the materials and techniques used. The decorative elements were modified and transformed to match their own belief of the ancient Christians in Egypt. ${ }^{4}$ Coptic art is a unique one during long Egyptian history. It began after thousands of years of the ancient Egyptian art, and before around fourteen decades of the Islamic art in Egypt. Moreover, it was created in a special social, spiritual, and economical circumstances. That's why, the Coptic art is a special interesting research area, and needs more studies focusing on its history, materials, techniques, styles, etc., especially when intervened with its earlier and later arts. ${ }^{5}$ Dating is another area of interest in Coptic art. Some historians rely only on the stylistic features and are skeptical of the results of radiocarbon analysis. Weaving techniques and dye analyses have been added as dating methods. Despite it is not entirely true, sometimes, the lack of results' precision in radiocarbon analysis was the main reason for this skepticism. ${ }^{6}$

The climate environment is the main cause of the ancient textile inevitable decay. Temperature causes thermal degradation of fibers, which is commonly called thermolysis or thermolytic degradation of both crystalline and amorphous phases in the absence of oxygen. This degradation is motivated and increased in the presence of oxygen, the non-specific oxidant agent, which attacks artworks wherever they are due

1 Van, et al., Pharaonic and early medieval Egyptian textiles, 1994.

Thomas, Coptic and Byzantine textiles found in Egypt, 2007.

Michael, The Creativity in Decoration Designs, (2011).

Saweros, Angels in Coptic tradition. Shedet, 2019.

2 Hofmann-de Keijzer et al., Dyes, dyeing techniques and dyestuff analysis, 2007.

Vogelsang-Eastwood, and Kolkman, Embroidery from the Arab world, 2010.

3 Michael, Revival of the Coptic Tapestry Decoration, Journal of Costume, 2016.

Thompson, Coptic textiles in the Brooklyn Museum, 1971.

4 Thomas, Coptic and Byzantine textiles found in Egypt, 2007.

Thompson, Coptic textiles in the Brooklyn Museum, 1971.

5 Van, et al., Pharaonic and early medieval Egyptian textiles, 1994.

Thomas, Coptic and Byzantine textiles found in Egypt, 2007.

Michael, The Creativity in Decoration Designs, 2011.

Thompson, Coptic textiles in the Brooklyn Museum, 1971.

Saweros, Thoughts on the Coptic Literature Heritage, 2015.

6 Van Strydonck et al., 14 C Dating Compared to Art Historical Dating, 2004. 
to its abundance and oxidative reaction. ${ }^{7}$ Light is called the enemy of ancient textiles due to its deteriorative effects on both fibers and dyes. It causes fading of dyes and decaying of fibers due to the photochemical degradation caused by the UV radiation, especially on the proteinous fibers, which are more vulnerable to light than the cellulosic ones. Light, in the presence of oxygen, can cause the photo-oxidation of fibers and dyes, resulting in breaking of molecular chains. ${ }^{8}$ The high humidity rate results in fiber swelling, color change, and mold growth. In the presence of acid gases and cumulative particulates, a high humidity rate can also cause acid hydrolysis and accelerate deteriorative reactions in fibers and dyes. ${ }^{9}$ The conservators of artworks, supported by the modern analytical techniques are entitled to stop the present deterioration agents, treat the artworks, and prevent further deterioration. ${ }^{10}$

The characterization of the textile fibers and coloring materials used is a fundamental step to achieve many conservation aims. ${ }^{11}$ It also helps dating and authenticating the textile fragments, based on the identified materials, stylish decorations, and weaving techniques along with the historical and textual data. ${ }^{12}$ Moreover, it is used in examining the textile properties, the present state of deterioration and conservation. ${ }^{13}$

For their mentioned above importance, authors used various investigation and analytical techniques, such as scanning electron microscopy coupled with energy dispersive X-ray spectroscopy unit (SEM-EDXS), stereo microscopy (SM), X-ray techniques, Fourier transformer infrared spectroscopy (FTIR), mass spectroscopy (MS), and high-performance liquid chromatography (HPLC). ${ }^{14}$ The results of these techniques, especially the cutting-edge ones, are the backbone of conservation studies. The obtained results revealed using both linen and natural wool at the beginning of the Coptic times. Later, natural silk was proven to be used. All fibers were used either in blank form or dyed with different natural dyestuffs, mordanted with many mineral mordants of aluminum, iron, copper. Moreover, the deterioration of fibers and dyes is also assayed in physical techniques such as SEM and chemical ones such as FTIR,

7 Odlyha,et al, Studies on woolen threads from historical tapestries, 2007.

Carr, and Lewis, An FTIR spectroscopic study of the photodegradation and thermal, 1993.

8 Yong-hua, et al, Research on the Aging, 2012.

Feller, Accelerated aging: photochemical and thermal aspects, 1995.

9 Feller, Accelerated aging: photochemical and thermal aspects, 1995.

10 Kabbani, Conservation a collaboration between art and science, 1997.

11 Schaffer, Fiber identification in ethnological textile artifacts, 1981.

Tímár-Balázsy, and Eastop, Chemical principles of textile conservation,1998.

Saltzman, Identifying dyes in textiles, 1992.

12 Van Strydonck et al., 14 C Dating Compared to Art Historical Dating, 2004.

Tímár-Balázsy, and Eastop, Chemical principles of textile conservation,1998.

Marouf, Identification and Characterization of Fibers and Weave Structures, 2010.

13 Schindler, and Finnimore, Chemical analysis of damage to textiles, 2005.

Jakes,et al. Infrared examination of fiber and particulate residue, 2007.

14 Yoder, The use of "soft" X-ray radiography in determining hidden construction, 2008.

Alexiou, et al, In From the burial to the textile conservation lab, 2015.

Amin, The documentation and treatment of a Coptic child's tunic in Egypt, 2019.

Abdel-Kareem and El-Nagar, Non-destructive methods to investigate the deterioration, 2005.

- 279 - Investigation and Analysis of Two Coptic Textile Fragments in Egypt 
Raman, and chromatography. The conservation plans of these degraded textiles and the similar ones are commonly based on these significant obtained results. ${ }^{15}$

The conservation issues presented in this work arise from the abandonment of the archaeological and historical heritage collections held in the Egyptian Agricultural Museum. According to the museum catalogue, the museum houses thousands of different heritage objects, with a wide range of physic-chemical, biological, and manmade deterioration. The main causes are the inappropriate museum environment and the absence of the necessary museum staff. The main critical problem of the present study corresponds to the two case-study fragments. Both are almost degraded and suffering from many deterioration phenomena, mainly because they are tightly locked up between two glass boards, and the minimal ventilation was inappropriately prevented. The deterioration phenomena were physically identified through the SEM micrographs, and chemically through the FTIR spectra of the investigated fibers. The present study aims to help rescue these Coptic textile fragments by attaining the first step, i.e. the investigation and analysis, to facilitate their future treatments.

\section{MATERIALS AND METHODS}

\subsection{The textile fragments and sampling}

The two Coptic textile fragments are exhibited in the Agricultural Museum in Dokki, Giza (Egypt). The first fragment (Figure 1a) with the museum record no. 185 (here and after called F185) dates to the $2^{\text {nd }}-3^{\text {rd }}$ century AD. It was fabricated in tapestry technique using beige and bluish-black wefts. This fragment was probably cut from a child's tunic. The design of the Coptic tunic (Figure 1b) shows the main parts highlighted, including the clavus (dashed box no. 1), shoulder embellishment (dashed box no. 2), and the lower embellishment (dashed box no. 3).

The fragment consists of two parts (main body and medallion) probably from a child tunic because the clavus is not as long as in a man's tunic. The size of the main body is ca. $44 \times 13 \mathrm{~cm}$. The size of the medallion is ca. $12 \times 12 \mathrm{~cm}$. The Coptic tunics were commonly ornamented with a single clavus (a vertical stripe or band of worn on the tunic in ancient Rome) that ran down the center, or two clavi that extended upon the shoulders down to the center or the end of the tunic on the front and back. ${ }^{16}$ The bluishblack threads and the blank ones were used in depicting the decorative human elements, which were intentionally removed from the decorated areas in the clavus and shoulder. The preserved elements are those of the ornaments in the separated medallion.

The second fragment (Figure 1c) is a textile fragment with the museum record no. 182 (here and after called F182). It dates approximately to the $5^{\text {th }}-6^{\text {th }}$ centuries AD. Its size is ca. $26.5 \times 5 \mathrm{~cm}$. It was fabricated in tapestry technique, using colorful beige,

15 Alexiou, et al, In From the burial to the textile conservation lab, 2015.

Abdel-Kareem,and El-Nagar, Non-destructive methods to investigate the deterioration, 2005.

Marouf and Saber, Treatment and Conservation of Archaeological Garment from, 2009.

16 Carroll, Looms and textiles of the Copts Collection of the California Academy of Sciences, 1988.

Pritchard, Clothing culture: collection of the Whitworth Art Gallery, 2006.

Davis, Coptic Christology in Late Antique and Medieval Egypt, 2008. 
coppery red, bluish-black, and light green wefts. It is probably a part of a Coptic textile panel or tunic, but it is rather thick, due to the strict combing of wefts during its weaving on the loom. The types of symbols and ornamental elements do not match the ones that were commonly used in decorating early Coptic tunics, from the early Coptic times. Therefore, it is probable that it was a part of a decorated textile panel or curtain, not a tunic. ${ }^{17}$ The differently dyed wefts are used in depicting animal and plant elements with symbolic features.

Both fragments are displayed in an inappropriate museum environment. They are almost degraded and suffering from many deterioration phenomena, mainly because they are tightly locked up between two glass boards, and the minimal required air ventilation was inappropriately prevented. This procedure probably caused or increased the fragility, brittleness, and color changes of the fragments, which were probably affected by other unknown deterioration factors a long time before locking up. No data are available about the history of the fragments before the present museum display.

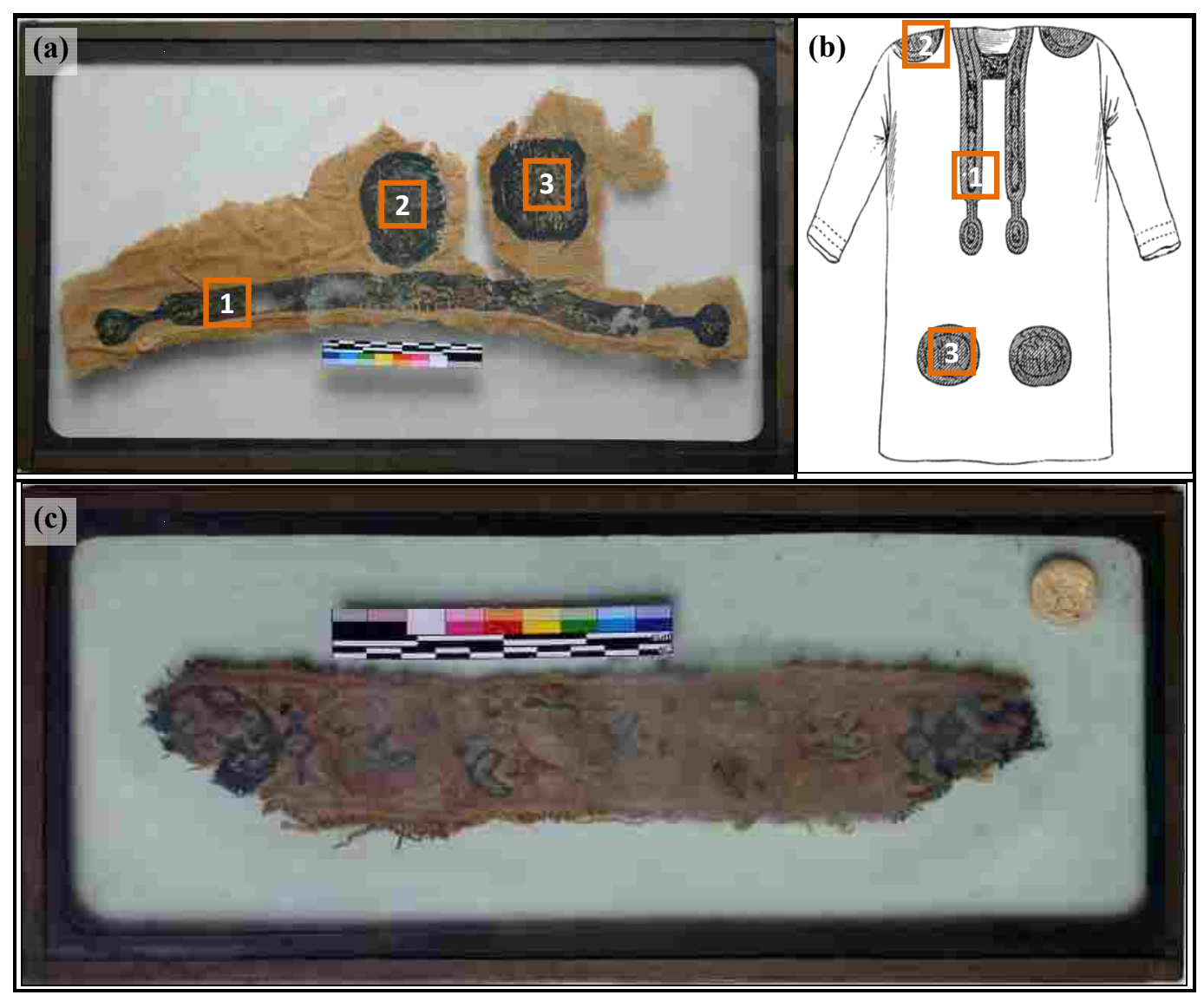

Fig. 1, The two fragments, a Fragment number F185. b Drawing of Coptic tunic design decorated with clavi and other embellishments with key numbers of techniques refer to the same parts in both the F185 and design ${ }^{18}$. c Fragments number F182.

17 Davis, Coptic Christology in Late Antique and Medieval Egypt, 2008.

Thomas, Coptic and Byzantine textiles found in Egypt, 2007.

18 Davis, Coptic Christology in Late Antique and Medieval Egypt, 2008.

- 281 - Investigation and Analysis of Two Coptic Textile Fragments in Egypt 
To investigate and analyze the two selected fragments, the glass boards were removed to collect the required micro-samples from the detaching fibers in fragile areas (Table 1). Nine micro-samples (F185/1-9) were collected from F185, including a pair of samples from the main body and the separated medallion (Figure 2a). Six micro-samples (F182/1-6) were collected from F182 (Figure 2b).

Table 1. The technical descriptions of the collected micro-samples

\begin{tabular}{lll}
\hline Samples & Fragment 1 (F185) & Fragment (F182) \\
\hline & F185/1, beige, warp, fragment & F182/1, beige, warp \\
& F185/2, beige, warp, medallion & F182/2, yellow, weft \\
& F185/3, beige, weft, fragment & F182/3, bluish-black F182/4, \\
& F185/4, beige, weft, medallion & light green \\
& F185/5, bluish-black, fragment & F182/5, coppery red \\
Collected micro-samples & F185/6, bluish-black, medallion & F182/6, old adhesive \\
& F185/7, blank, fragment \\
& F185/8, blank, medallion \\
& F185/9, beige, decorative band, \\
& \\
\hline
\end{tabular}

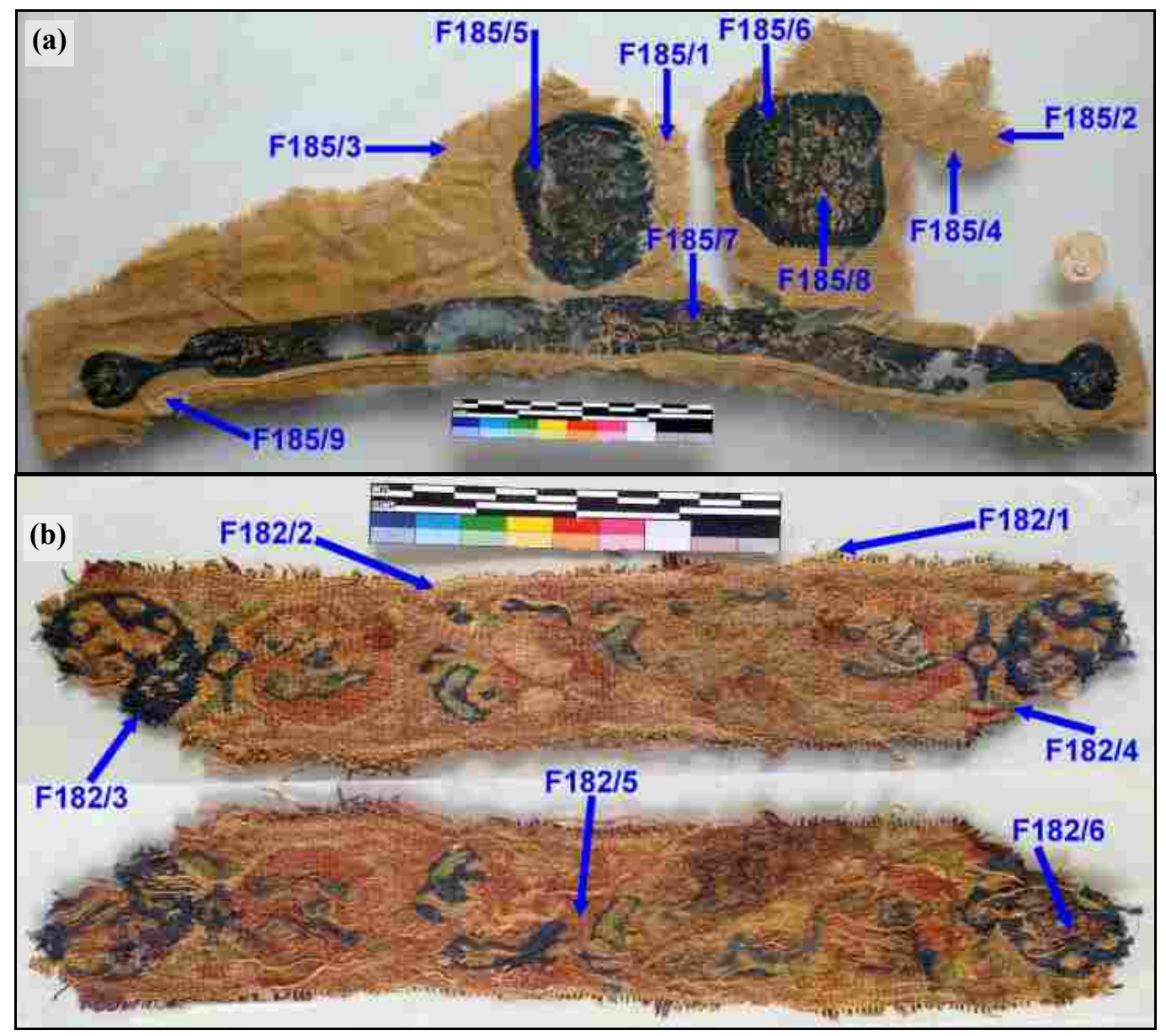

Fig. 2, The two fragments with sampling locations after removal of the glass boards, a F185. b F182. 


\subsection{Stereo Microscope (SM)}

A Stereo Microscope SM (SMZ800, Nikon) coupled with EOS 700D Canon camera was used to identify the weave structure and the deterioration phenomena in the objects.

\subsection{Scanning electron microscope-energy dispersive x-ray spectroscopy (SEM- EDXS)}

An SEM (Quanta 3D FEG, FEI Company, USA) coupled with an EDXS was used to examine the types and ratios of deterioration phenomena in the two fragments. The SEM was used in the secondary electron imaging (SEI) to identify the type(s) of fibers thanks to their morphological features. ${ }^{19}$ The EDXS unit was used to identify the dyes' mordants and types of dust and soot. ${ }^{20}$ The investigation conditions were as follows: the energy of the beam was $20 \mathrm{kV}$; the acceleration voltage was at $10 \mathrm{~mm}$ working distance and a spot size of $5.5(1 \mathrm{kV} / 10 \mathrm{pA})$ with a scale range of $10-50 \mu \mathrm{m}$. The spot size was $7(20 \mathrm{kV} / 4 \mathrm{nA})$ with a scale of $200 \mu \mathrm{m}$. Due to the non-uniform surface and thickness of the investigated fibers, each EDX analyzed area for each sample was repeated twice, with the averages being then calculated, for accurate results. The EDXS detector was calibrated, but not for standard quantification method. The samples destined to the SEM-EDXS investigations were directly investigated without any prior preparation or coating.

\subsection{High-performance liquid chromatography-diode array detection-mass spectrometry (HPLC-DAD-MS)}

To identify the textile dyes, HPLC-DAD-MS was used. The present study utilized an HPLC system (Agilent 1200 series system, Agilent Technologies, Waldbronn, Germany, in the in the University of Technology, Gdanesk), coupled with MS (Agilent Q-TOF MS 6538, Santa Clara, CA) operated in a negative mode to give the highest sensitivity for carboxylic acids and phenols, under the same chromatographic conditions, equipped with an auto-sampler G1313A, pump G1311A and thermostated column compartment G1316A. The analytes were monitored with DAD and MS online connected and characterized by retention times, UV-vis, and mass spectra. The components of the extracts were separated on a reversed-phase column (ZORBAX SB--C18, 4.6×150 mm, 3.5 $\mu \mathrm{m}$, Agilent Technologies, USA). It was operated in negative mode. Agilent MassHunter software (B.07.05) was used to control the chromatographic system. A gradient of methanol/acetonitrile and water was used to ensure optimal resolution for the different chemical compounds. The mobile phase comprised: (A) $0.1 \%$ formic acid in water, (B) $0.1 \%$ formic acid in $\mathrm{ACN} / \mathrm{MeOH}(1: 1 ; \mathrm{v} / \mathrm{v})$, isocratic gradient of $90 \mathrm{~A}+10 \mathrm{~B}$ for $0-3 \mathrm{~min}, 0 \mathrm{~A}+100 \mathrm{~B}$ for 20-30 min. The elution was performed at $0.5 \mathrm{~mL} / \mathrm{min}$ flow rate and $20 \mu \mathrm{L}$ injection volume. For the $\mathrm{MS}$; drying gas flow $\left(12 \mathrm{~L} \mathrm{~min}^{-1}\right)$, drying gas temperature $\left(300 \mathrm{C}^{\circ}\right)$,

19 Alexiou, et al., In From the burial to the textile conservation lab, 2015.

20 Uring, et al, The Bayeux embroidery: a dust deposition assessment , 2018.

- 283 - Investigation and Analysis of Two Coptic Textile Fragments in Egypt 
nebulizer pressure (50 psi), ionization voltage $(4 \mathrm{kv})$, acquisition in production scan (mass range $50-650 \mathrm{~m} / \mathrm{z}, \mathrm{CE} 25 \mathrm{eV}$ ).

The textile samples were treated to extract the dyes prior to analysis. The dyes were extracted from the micro-thread samples $(0.2 \mathrm{mg})$ in an ultrasonic bath for 1 hour $(4 \times 15 \mathrm{~min})$ at $\leq 40^{\circ} \mathrm{C}$ using $500 \mu \mathrm{L}$ of a solution containing $0.4 \mathrm{M}$ hydrofluoric acid /methanol /acetonitrile/ DMSO (2:1:1:1, v/v/v/v). The mixtures were centrifuged at $9000 \mathrm{rpm}$ for 5 minutes, and the supernatants evaporated almost to dryness under a stream of nitrogen at a pressure of $15 \mathrm{psi}$ at room temperature. The residues were dissolved in $300 \mu \mathrm{L}$ of $\mathrm{ACN} / \mathrm{MeOH} / \mathrm{DMSO}(1: 1: 1, \mathrm{v} / \mathrm{v} / \mathrm{v})$, out of which $20 \mu \mathrm{L}$ was injected into the HPLC column. ${ }^{21}$

\subsection{Fourier transformer infrared spectroscopy-attenuated total reflection (FTIR-ATR)}

To identify and characterize the fibers and the old adhesive, an FTIR-ATR (Nicolet 8700, Thermo Fisher Scientific, Waltham, USA) equipped with an MCT detector was used. The spectra were collected with ATR Golden Gate appliance in the spectral range from 4000 to $400 \mathrm{~cm}^{-1}$ with a $4 \mathrm{~cm}^{-1}$ resolution at room temperature. The spectral analysis was controlled by Omnic software package (Thermo Fisher Scientific, Waltham, USA). Although FTIR-ATR helps identifying the type(s) of fibers and other materials, e.g. organic adhesives, it does not help identify the type(s) of dyes. $^{22}$ The samples destined to the FTIR-ATR investigations were directly investigated without any prior preparation.

\section{RESULTS AND DISCUSSION}

\subsection{Weaving techniques and characterization}

The SM obtained images showed that the warps and wefts of F185 were woven in the plain tapestry technique $1 / 1$. Beige warps and wefts were used in the fragment background. Bluish-black wefts were used in the elemental decorating of the medallion and clavus. A longitudinal narrow embroidered stripe was used in ornamenting the fragments using the chain stitch pattern. The linear density is 17 for warps, and 19 for wefts. The threads No./cm is 12 for warps, and 21 for wefts. The torsion direction is "S" for both warps and wefts (Figure 3a, b). F182 was also woven in the plain tapestry technique $1 / 1$. Beige warps were used. Beige, coppery red, bluish-black, and light green wefts were used in depicting the decorative elements of the fragment. The linear density is 10 for warps, and 20 for wefts. The threads No./cm is 7 for warps, and 40 for wefts. The torsion direction is also "S" for both warps and wefts (Figure 3c).

21 Witkowski, et al, Identification of orcein and selected natural dyes in 14th and 15th century, 2017. Otłowska,et al, Chromatographic and Spectroscopic Identification and Recognition of Natural Dyes, 2018.

22 Trojanowicz, et al, Chromatographic investigation of dyes extracted from Coptic textiles, 2004. Kavkler, et al, FTIR spectroscopy of biodegraded historical textiles, 2011. 


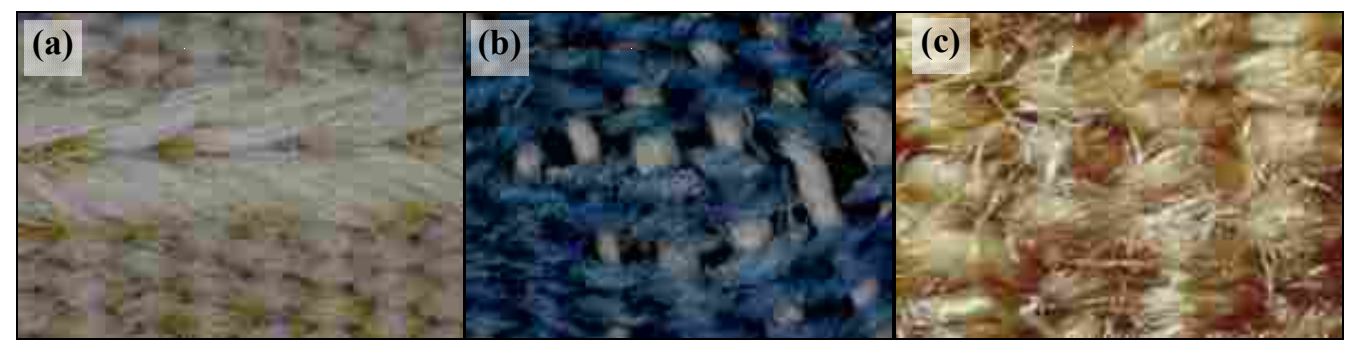

Fig. 3, The SM micrographs of weaving techniques, a beige plain tapestry $1 / 1$ and embroidery of F185. b bluish-black plain tapestry $1 / 1$ of F185. c beige plain tapestry $1 / 1$ of F182.

\subsection{Identification of fibers}

The SEM obtained micrographs of the morphological features of the examined micro-samples compared to the morphological features of the standard textile fibers revealed that the beige warps and wefts of F185 were made from natural sheep wool and so the bluish-black wefts (Figure 4a, b), except for samples no. F185/7 and F185/8 which were linen (Figure 4c). The SEM micrographs of F182 revealed that the beige warps and the wefts were from natural sheep wool and so the other dyed wefts (Figures $4 \mathrm{~d}, \mathrm{e}, \mathrm{f}$ ). SEM is commonly used in the field of textile studies to identify the types of fibers and their characterization. ${ }^{23}$

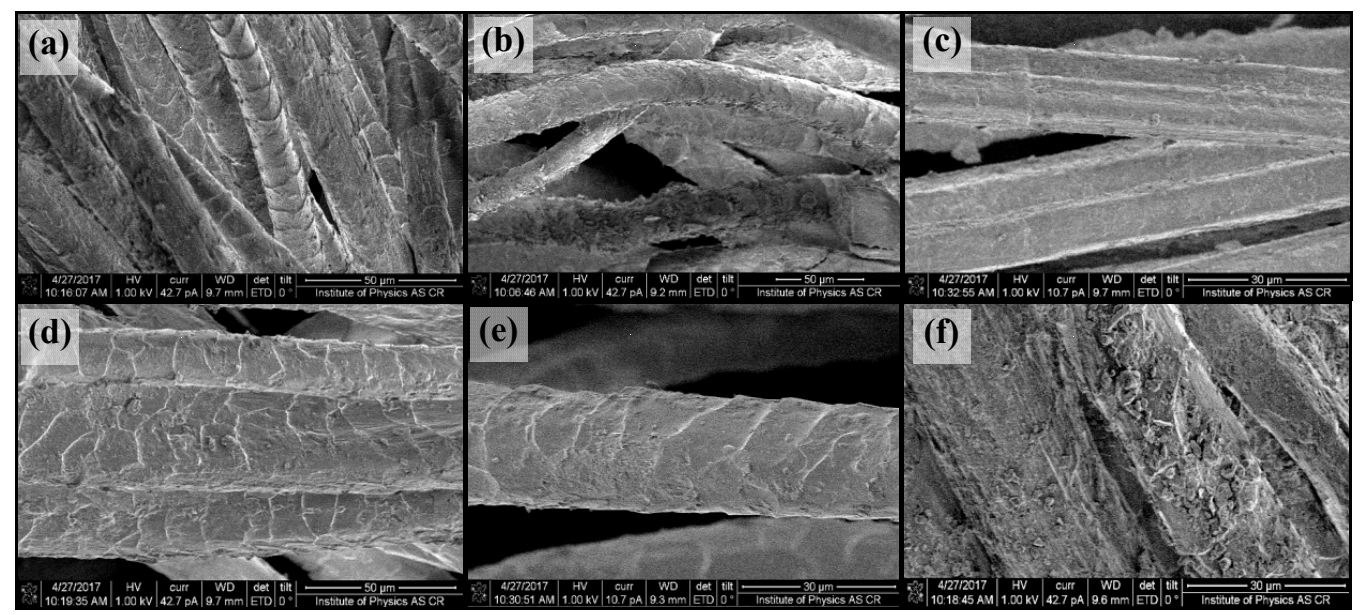

Fig. 4, The SEM micrographs, a wool warp. b wool wefts. c linen blank ornaments of F185. d wool warps. e beige wool wefts. f bluish-black wool wefts of F182.

The analytical results of FTIR-ATR spectroscopy applied to the selected microsamples of F185 (figure 5) and F182 (figure 6) confirmed the SEM results on the morphological identification of fibers' types and their deterioration. The FTIR results revealed that samples no. F185/1, F185/2, F185/3, F185/4, F185/5, F185/6, and F185/9 from F185 and samples no. F182/1, F182/2, F182/3, F182/4, and F182/5 from F182 were protein fibers of natural sheep wool. The peaks at $\sim 1652 \mathrm{~cm}^{-1}, \sim 1544 \mathrm{~cm}^{-1}$, $\sim 1235 \mathrm{~cm}^{-1}, \sim 1122 \mathrm{~cm}^{-1}$, and $\sim 1070 \mathrm{~cm}^{-1}$ refer to $-\mathrm{C}=\mathrm{O}$ stretching amide $\mathrm{I},-\mathrm{NH}$

23 Alexiou, et al., In From the burial to the textile conservation lab, 2015.

Otłowska,et al, , Chromatographic and Spectroscopic Identification and Recognition of Natural Dyes, 2018.

- 285 - Investigation and Analysis of Two Coptic Textile Fragments in Egypt 
bending amide II, -N-H \& -N-OC mixed vibration amide III, -SO2-S-cysteine dioxide, and -SO-S- cysteine monoxide respectively. ${ }^{24}$

The FTIR spectra of samples no. F185/7 and F185/8 from F185 revealed that the blank decoration threads in the main body and the separated medallion were from the cellulosic origin, in particular linen, which was commonly used in the textile industry throughout Egyptian history as reported by Herodotus for ancient Egypt and during Coptic times. The novelty in this fragment is using linen threads in the decorative elements while wool threads were used in the plain background, contrary to what is commonly known. ${ }^{25}$ The vibrations at $\sim 4000-2995 \mathrm{~cm}^{-1}, \sim 2900 \mathrm{~cm}^{-1}, \sim 1430 \mathrm{~cm}^{-1}$, $\sim 1375 \mathrm{~cm}^{-1}, \sim 1280 \mathrm{~cm}^{-1}$, and $\sim 900 \mathrm{~cm}^{-1}$ distinguished both crystalline and amorphous cellulose. The bands at $\sim 1315 \mathrm{~cm}^{-1}, \sim 1335 \mathrm{~cm}^{-1}$, and $\sim 1370 \mathrm{~cm}^{-1}$ are due to the $\mathrm{COH}$ and $\mathrm{HCC}$ bending vibrations. The bands at $\sim 1430 \mathrm{~cm}^{-1}, \sim 1370 \mathrm{~cm}^{-1}$, $\sim 1335 \mathrm{~cm}^{-1}$, and $\sim 1280 \mathrm{~cm}^{-1}$ corresponded to the crystalline phase of cellulose, while the bands at $\sim 900 \mathrm{~cm}^{-1}$ matched the amorphous phase. ${ }^{26}$ Wool and linen fibers were the most common materials in Coptic textiles woven with the tapestry technique. Other authors, e.g. Abdel-Kreem and El-Nagar, Ahmed et al., and Karydis et al. ${ }^{27}$ identified similar components when examining Coptic textile fragments.

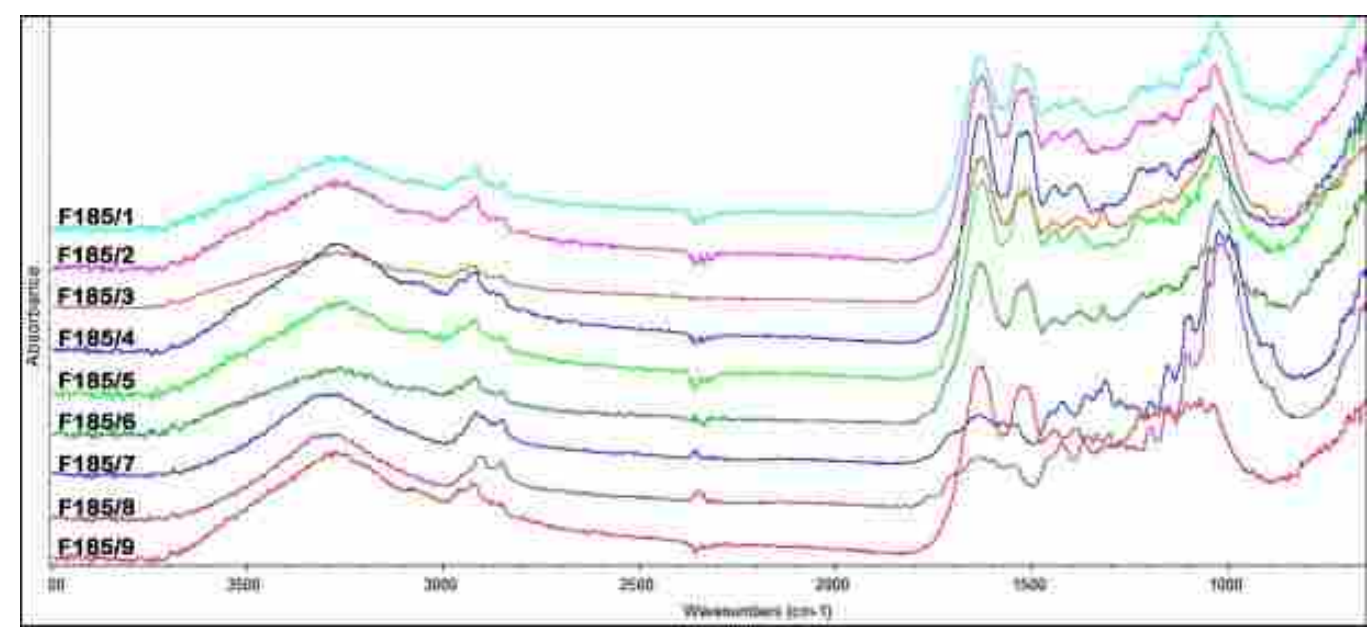

Fig. 5, The FTIR spectra of F185 samples suggest that F185/1, F185/2, F185/3, F185/4, F185/5, F185/6 and F185/9 are wool; F185/7 and F185/8 are linen.

24 Hofmann-de Keijzer et al, Dyes, dyeing techniques and dyestuff analysis, 2007.

Odlyha, and Theodorakopoulos, Studies on woolen threads from historical tapestries, 2007.

25 Karydis, et al, The unpublished Coptic textiles of the monastery of St. John the theologian, 2019.

Lucas, and Harris, Ancient Egyptian materials and industries, 2012.

26 Proniewicz, et al, FT-IR and FT-Raman study of hydrothermally degradated cellulose, 2001.

Garside, and Wyeth, Identification of cellulosic fibres by FTIR spectroscopy, 2006.

27 Abdel-Kareem, and El-Nagar, Non-destructive methods to investigate the deterioration, 2005.

Karydis, et al, The unpublished Coptic textiles of the monastery of St. John the theologian, 2019.

Ahmed, et al, Identification of natural dyes in rare Coptic textile using HPLC-DAD, 2017. 


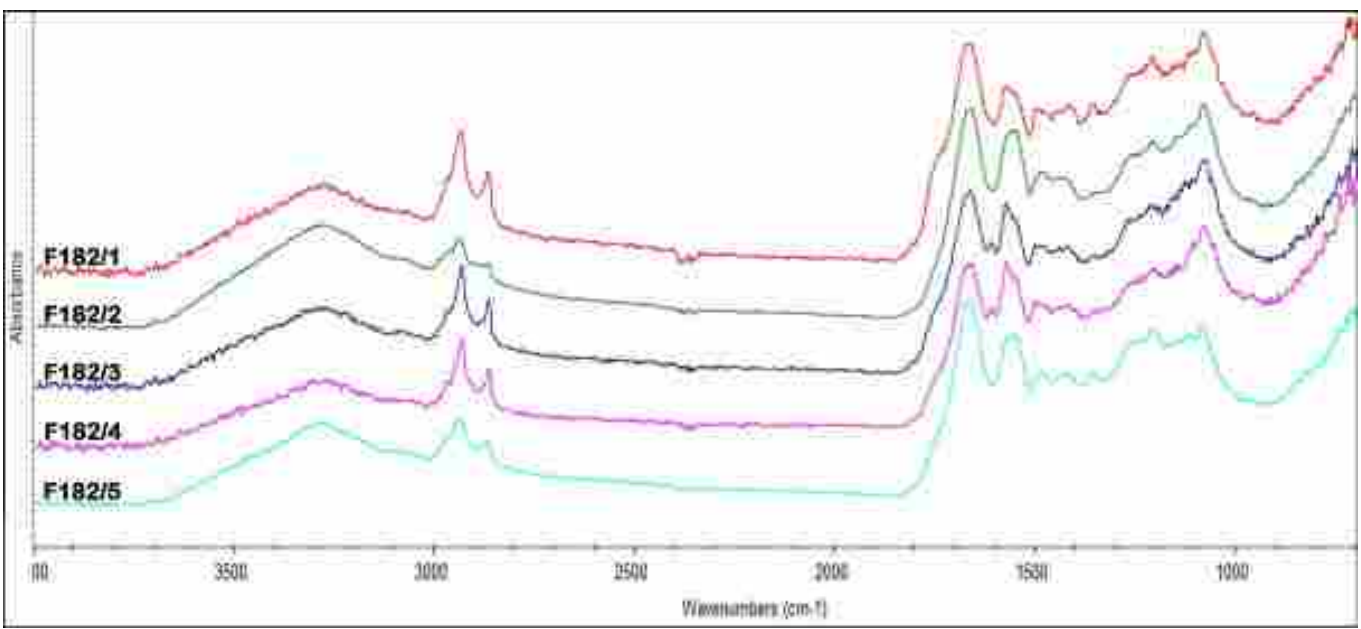

Fig. 6, The FTIR spectra of F182 samples suggest that F182/1, F182/2, F182/3, F182/4, and F182/5 are wool fibers.

\subsection{IDENTIFICATION OF DYES}

\subsubsection{Weld dye}

The results of the beige samples no. F185/1, F185/2, F185/3, F185/4, F185/9 from F185, and sample no. F182/1 from F182 are summarized in Table 3. Weld dye (Reseda luteola) was confirmed by identifying the following compounds: apigenin-Cdiglucoside characterized by the molecular ion at $593 \mathrm{~m} / \mathrm{z}$, at $t \mathrm{R} 9.7 \mathrm{~min}$, luteolin-3,7'O-diglucoside $(609 \mathrm{~m} / \mathrm{z})$ at $t \mathrm{R} 10.6 \mathrm{~min}$, luteolin-7-O-glucoside $(447 \mathrm{~m} / \mathrm{z})$ at $t \mathrm{R} 11.4$ min, chrysoeriol-O-glucoside $(461 \mathrm{~m} / \mathrm{z})$ at $t \mathrm{R} 12.3 \mathrm{~min}$, apigenin-7-O-glucoside (431 $\mathrm{m} / \mathrm{z}$ ) at $t \mathrm{R} 12.4 \mathrm{~min}$, luteolin-4'-O-glucoside $(447 \mathrm{~m} / \mathrm{z})$ at $t \mathrm{R} 12.9 \mathrm{~min}$, luteolin (285 $\mathrm{m} / \mathrm{z})$ at $t \mathrm{R} 14.3 \mathrm{~min}$, apigenin $(269 \mathrm{~m} / \mathrm{z})$ at $t \mathrm{R} 15.4 \mathrm{~min}$, and chrysoeriol $(299 \mathrm{~m} / \mathrm{z})$ at $t \mathrm{R} 15.6 \mathrm{~min}$. The result of the yellow sample no. F182/2 from F182 (Table 3) confirmed the use of weld dye, in addition to madder (see data below). All the mentioned compounds of weld dye (except for luteolin-4'-O-glucoside, apigenin-Cdiglucoside) are also identified in sample no. F182/2 from F182. The result of the light green sample no. F182/4 from F182 (Table 2) confirms the use of weld, in addition to indigo. Apigenin-C-diglucoside, luteolin-7-O-glucoside, chrysoeriol-Oglucoside, luteolin 4'-O-glucoside, apigenin 7-O-glucoside, luteolin, apigenin, and chrysoeriol were identified. ${ }^{28}$ Weld was commonly used in dyeing historical textiles to obtain different shades of yellow, or mixed with other dyes for different shades of brown, orange, green, and black. It was one of the most famous yellow dye in the ancient East and Europe. ${ }^{29}$

28 Peggie, et al, Towards the identification of characteristic minor components from textiles dyed with weld (Reseda luteola L.) and those dyed with Mexican cochineal (Dactylopius coccus Costa), 2008. Troalen, et al, Historical textile dyeing with Genista tinctoria, 2014.

Moiteiro, et al, HPLC quantification of dye flavonoids in Reseda luteola L. from Portugal, 2008.

Marques, et al, Characterization of weld and spurge, 2009.

Ortega et al, Material analysis versus historical dye recipes, 2019.

29 Marques, et al, Characterization of weld and spurge, 2009.

Ortega et al, Material analysis versus historical dye recipes, 2019.

- 287 - Investigation and Analysis of Two Coptic Textile Fragments in Egypt 
Table 2. Results of the HPLC-DAD-MS for the different dyes of the two case-study fragments

\begin{tabular}{|c|c|c|c|c|c|c|}
\hline No. & Color & $t \mathrm{R}(\mathrm{min})$ & $\begin{array}{l}{[\mathrm{M}-\mathrm{H}]-} \\
m / z^{*}\end{array}$ & $\begin{array}{l}\text { Detected } \\
\text { compounds }\end{array}$ & $\begin{array}{l}\text { Raw } \\
\text { formula }\end{array}$ & $\begin{array}{l}\text { Dye } \\
\text { source }\end{array}$ \\
\hline$\overline{F 185 / 1}$ & \multirow[t]{9}{*}{ Beige } & 9.7 & 593 & Apigenin-C-diglucoside & $\mathrm{C}_{27} \mathrm{H}_{30} \mathrm{O}_{15}$ & \multirow{9}{*}{$\begin{array}{l}\text { Weld, Reseda } \\
\text { luteola }\end{array}$} \\
\hline F185/2 & & 10.6 & 609 & Luteolin-3,7'-O-diglucoside & $\mathrm{C}_{27} \mathrm{H}_{30} \mathrm{O}_{16}$ & \\
\hline F185/2 & & 11.4 & 447 & Luteolin-7-O-glucoside & $\mathrm{C}_{21} \mathrm{H}_{20} \mathrm{O}_{11}$ & \\
\hline F185/3 & & 12.3 & 461 & Chrysoeriol-O-glucoside & $\mathrm{C}_{22} \mathrm{H}_{22} \mathrm{O}_{11}$ & \\
\hline F185/4 & & 12.4 & 431 & Apigenin-7-O-glucoside & $\mathrm{C}_{21} \mathrm{H}_{20} \mathrm{O}_{10}$ & \\
\hline F185/9 & & 12.9 & 447 & Luteolin-4'-O-glucoside & $\mathrm{C}_{21} \mathrm{H}_{20} \mathrm{O}_{11}$ & \\
\hline \multirow{3}{*}{ F182/1 } & & 14.3 & 285 & Luteolin & $\mathrm{C}_{15} \mathrm{H}_{10} \mathrm{O}_{6}$ & \\
\hline & & 15.4 & 269 & Apigenin & $\mathrm{C}_{15} \mathrm{H}_{10} \mathrm{O}_{5}$ & \\
\hline & & 15.6 & 299 & Chrysoeriol & $\mathrm{C}_{16} \mathrm{H}_{12} \mathrm{O}_{6}$ & \\
\hline $\mathrm{F} 185 / 5$ & \multirow{3}{*}{$\begin{array}{l}\text { Bluish- } \\
\text { black }\end{array}$} & 18.3 & 501 & Unknown & Unknown & \multirow{3}{*}{$\begin{array}{l}\text { Indigo, } \\
\text { Indigofera } \\
\text { tinctoria }\end{array}$} \\
\hline F185/6 & & 19.6 & 261 & Indigotin & $\mathrm{C}_{16} \mathrm{H}_{10} \mathrm{~N}_{2} \mathrm{O}_{2}$ & \\
\hline \multirow{11}{*}{$\begin{array}{l}\mathrm{F} 187 / 2 \\
\mathrm{~F} 182 / 2\end{array}$} & & 20.5 & 261 & Indirubin & $\mathrm{C}_{16} \mathrm{H}_{10} \mathrm{~N}_{2} \mathrm{O}_{2}$ & \\
\hline & \multirow[t]{10}{*}{ Yellow } & 10.6 & 609 & Luteolin-3,7'-O-diglucoside & $\mathrm{C}_{27} \mathrm{H}_{30} \mathrm{O}_{16}$ & \multirow{2}{*}{$\begin{array}{l}\text { Weld, Reseda } \\
\text { luteola }\end{array}$} \\
\hline & & 11.4 & 447 & Luteolin-7-O-glucoside & $\mathrm{C}_{21} \mathrm{H}_{20} \mathrm{O}_{11}$ & \\
\hline & & 12.3 & 461 & Chrysoeriol-O-glucoside & $\mathrm{C}_{22} \mathrm{H}_{22} \mathrm{O}_{11}$ & \multirow{8}{*}{$\begin{array}{l}\text { + Madder, } \\
\text { Rubia tinctorum }\end{array}$} \\
\hline & & 12.4 & 431 & Apigenin-7-O-glucoside & $\mathrm{C}_{21} \mathrm{H}_{20} \mathrm{O}_{10}$ & \\
\hline & & 14.3 & 285 & Luteolin & $\mathrm{C}_{15} \mathrm{H}_{10} \mathrm{O}_{6}$ & \\
\hline & & 15.4 & 269 & Apigenin & $\mathrm{C}_{15} \mathrm{H}_{10} \mathrm{O}_{5}$ & \\
\hline & & 15.6 & 299 & Chrysoeriol & $\mathrm{C}_{16} \mathrm{H}_{12} \mathrm{O}_{6}$ & \\
\hline & & 17.2 & 283 & Munjistin & $\mathrm{C}_{15} \mathrm{H}_{8} \mathrm{O}_{6}$ & \\
\hline & & 19.3 & 239 & Alizarin & $\mathrm{C}_{14} \mathrm{H}_{8} \mathrm{O}_{4}$ & \\
\hline & & 21.8 & 255 & Purpurin & $\mathrm{C}_{14} \mathrm{H}_{8} \mathrm{O}_{5}$ & \\
\hline \multirow[t]{10}{*}{ F182/4 } & \multirow{10}{*}{$\begin{array}{l}\text { Light } \\
\text { green }\end{array}$} & 9.7 & 593 & Apigenin-C-diglucoside & $\mathrm{C}_{27} \mathrm{H}_{30} \mathrm{O}_{15}$ & \multirow{10}{*}{$\begin{array}{l}\text { Indigo, } \\
\text { Indigofera } \\
\text { tinctoria } \\
+ \text { weld, Reseda } \\
\text { luteola }\end{array}$} \\
\hline & & 11.4 & 447 & Luteolin-7-O-glucoside & $\mathrm{C}_{21} \mathrm{H}_{20} \mathrm{O}_{11}$ & \\
\hline & & 12.3 & 461 & Chrysoeriol-O-glucoside & $\mathrm{C}_{22} \mathrm{H}_{22} \mathrm{O}_{11}$ & \\
\hline & & 12.9 & 447 & Luteolin-4'-O-glucoside & $\mathrm{C}_{21} \mathrm{H}_{20} \mathrm{O}_{11}$ & \\
\hline & & 12.4 & 431 & Apigenin-7-O-glucoside & $\mathrm{C}_{21} \mathrm{H}_{20} \mathrm{O}_{10}$ & \\
\hline & & 14.3 & 285 & Luteolin & $\mathrm{C}_{15} \mathrm{H}_{10} \mathrm{O}_{6}$ & \\
\hline & & 15.4 & 269 & Apigenin & $\mathrm{C}_{15} \mathrm{H}_{10} \mathrm{O}_{5}$ & \\
\hline & & 15.6 & 299 & Chrysoeriol & $\mathrm{C}_{16} \mathrm{H}_{12} \mathrm{O}_{6}$ & \\
\hline & & 19.4 & 261 & Indigotin & $\mathrm{C}_{16} \mathrm{H}_{10} \mathrm{~N}_{2} \mathrm{O}_{2}$ & \\
\hline & & 20.1 & 262 & Indirubin & $\mathrm{C}_{16} \mathrm{H}_{10} \mathrm{~N}_{2} \mathrm{O}_{2}$ & \\
\hline \multirow[t]{5}{*}{$\mathrm{F} 182 / 5$} & \multirow{5}{*}{$\begin{array}{l}\text { Coppery } \\
\text { red }\end{array}$} & 17.2 & 283 & Munjistin & $\mathrm{C}_{15} \mathrm{H}_{8} \mathrm{O}_{6}$ & \multirow{5}{*}{$\begin{array}{l}\text { Madder, Rubia } \\
\text { tinctorum }\end{array}$} \\
\hline & & 17.5 & 299 & Pseudopurpurin & $\mathrm{C}_{15} \mathrm{H}_{8} \mathrm{O}_{7}$ & \\
\hline & & 19.3 & 239 & Alizarin & $\mathrm{C}_{14} \mathrm{H}_{8} \mathrm{O}_{4}$ & \\
\hline & & 21.8 & 255 & Purpurin & $\mathrm{C}_{14} \mathrm{H}_{8} \mathrm{O}_{5}$ & \\
\hline & & 24.08 & 253 & Rubiadin & $\mathrm{C}_{15} \mathrm{H}_{10} \mathrm{O}_{4}$ & \\
\hline
\end{tabular}

$t R$ (Retention Time), * (Mass spectra acquired in High resolution mode)

\subsubsection{Indigo dye}

The results for the bluish-black samples no. F185/5, F185/6 from F185 and sample no. F182/3 from F182 (Table 3) revealed the use of an indigoid dye. Indigotin and indirubin were identified at $261 \mathrm{~m} / \mathrm{z}$ in $t \mathrm{R} 19.6$ and $20.5 \mathrm{~min}$. respectively. Another unknown compound was detected at $501 \mathrm{~m} / \mathrm{z}$ in $t \mathrm{R} 18.3 \mathrm{~min}$, probably 
pseudoindirubin. Both indigotin and indirubin were also identified in the light green sample no. F182/4 from F182, in addition to weld-related compounds, as detailed above. It was very common to dye fabrics and threads using a blue dye and then a yellow one to obtain a green color. Indigotin and indirubin compounds are characteristic of indigo (Indigofera tinctoria) and woad (Isatis tinctoria), used in dyeing historical textiles all over the world with different shades of blue, bluish-black, and mixed colors such as green, purple, etc. ${ }^{30}$ Therefore, it is impossible to confirm which dye was used in the bluish-black and light green samples, whether indigo or woad. ${ }^{31}$ To identify the type of blue dye used, one should rely on the archaeological and historical evidence, since laboratory techniques cannot distinguish between indigo and woad. ${ }^{32}$ On the premises of the social and economic situation of the Egyptian Copts, and the cultivation of indigo in ancient Egypt, one can conclude that the identified Indigotin and indirubin correspond to the use of Indigofera tinctoria, not Isatis tinctoria. Similar results were reported in the literature. ${ }^{33}$

\subsubsection{Madder dye}

The obtained results for the yellow sample no. F182/2 from F182 (Table 3) revealed the use of madder dye (Rubia tinctorum) in addition to weld dye, as detailed above in the beige samples no. F185/1, F185/2, F185/3, F185/4, F185/9 from F185. Munjistin was identified at $283 \mathrm{~m} / \mathrm{z}$ in $t \mathrm{R} 17.2 \mathrm{~min}$, pseudopurpurin at $299 \mathrm{~m} / \mathrm{z}$ in $t \mathrm{R}$ $17.5 \mathrm{~min}$, alizarin was identified at $239 \mathrm{~m} / \mathrm{z}$ in $t \mathrm{R} 19.3 \mathrm{~min}$, purpurin at $255 \mathrm{~m} / \mathrm{z}$ in $t \mathrm{R}$ 21.8 min. Moreover, the coppery red sample no. F182/5 from F182 (Table 3) was also produced with a madder-type dye. Both alizarin and purpurin were identified, in addition to rubiadin at $253 \mathrm{~m} / \mathrm{z}$ in $t \mathrm{R} 24.08 \mathrm{~min}$, and traces of munjistin at $283 \mathrm{~m} / \mathrm{z}$ in $t \mathrm{R} 17.2 \mathrm{~min}$, and pseudopurpurin at $299 \mathrm{~m} / \mathrm{z}$ in $t \mathrm{R} 17.5 \mathrm{~min}$. The peak area ratios of alizarin versus purpurin were clearly larger than unity, thus proving the occurrence of Rubia tinctorum madder-type dye, and ruling out other madder types. Similar results were reported in the Coptic textiles dating to different periods. ${ }^{34}$

\subsection{Identification of dyes' mordants}

The results of the EDXS analysis for the different dyed and undyed microsamples of both fragments (Table 3) revealed the presence of many chemical

30 Ortega et al, Material analysis versus historical dye recipes, 2019

Mouri, et al, Analysis of dyes in textiles from the Chehrabad salt mine in Iran, 2014.

Cooksey, Indigo: an annotated bibliography, 2007.

31 Otłowska, et al., Chromatographic and Spectroscopic Identification and Recognition of Natural Dyes, 2018.

Ortega et al, Material analysis versus historical dye recipes, 2019.

Mouri, et al, Analysis of dyes in textiles from the Chehrabad salt mine in Iran, 2014.

32 Cooksey, Tyrian purple: 6, 6'-dibromoindigo and related compounds, 2001.

33 Trojanowicz, et al, Chromatographic investigation of dyes extracted from Coptic textiles, 2004.

Ahmed, et al, Identification of natural dyes in rare Coptic textile using HPLC-DAD, 2017.

Abdel-Kareem, Identification of dyestuffs in a rare Coptic garment, 2010.

34 Trojanowicz, et al, Chromatographic investigation of dyes extracted from Coptic textiles, 2004.

Karydis, et al, The unpublished Coptic textiles of the monastery of St. John the theologian, 2019.

Ahmed, et al, Identification of natural dyes in rare Coptic textile using HPLC-DAD, 2017.

Abdel-Kareem, Identification of dyestuffs in a rare Coptic garment, 2010. 
elements, namely C, N, O, F, Na, Mg, Al, Si, P, S, Cl, K, Sn, Ca, I, and Fe in most of the analytes. ${ }^{35} \mathrm{Al}$ element, which might correspond to the use of alum $\left(\mathrm{KAl}\left(\mathrm{SO}_{4}\right)_{2} \cdot 12 \mathrm{H}_{2} \mathrm{O}\right)$ as a mordant. The presence of $\mathrm{Fe}$ in the two blank samples no. $\mathrm{F} 185 / 7$ and $\mathrm{F} 185 / 8$ refers to impossibility of using ferrous sulfate $\left(\mathrm{FeSO}_{4}\right)$ as a mordant in the other dyed samples. If it was identified as mordant, it would be identified only in the dyed fibers, not in the blank ones. A minor amount of Al also identified in the same blank samples, but this minor amount might be attributed to soiling matters. The presence of Sn in samples F185/3, F185/4, F185/9, F182/2, and F182/5 may refer to the possibility of using stannous chloride $\left(\mathrm{SnCl}_{2}\right)$ as a mordant. ${ }^{36}$

Table 3. Results of the EDXS analysis for the micro-samples of the two case-study fragments

\begin{tabular}{|c|c|c|c|c|c|c|c|c|c|c|c|c|c|c|c|c|c|}
\hline \multirow{2}{*}{ No. } & \multirow{2}{*}{ color } & \multicolumn{16}{|c|}{ Wt\% detected elements } \\
\hline & & $\bar{C}$ & $\bar{N}$ & $\mathbf{O}$ & $\mathbf{F}$ & $\mathbf{N a}$ & Mg & $\overline{A l}$ & $\mathbf{S i}$ & $\mathbf{P}$ & $\mathbf{S}$ & $\mathbf{C l}$ & $\overline{\mathbf{K}}$ & Sn & $\mathbf{C a}$ & $\mathbf{I}$ & $\mathbf{F e}$ \\
\hline F185/1 & Beige & 29.9 & 20.2 & 36.8 & 0 & 2.68 & 0.48 & 0.49 & 1.66 & 0.18 & 2.64 & 0.4 & 0.3 & 0 & 3.5 & 0 & 0.7 \\
\hline F185/2 & Beige & 29.8 & 20.7 & 36.7 & 0 & 2.63 & 0.46 & 0.47 & 1.52 & 0.23 & 2.64 & 0.62 & 0.42 & 0 & 3.17 & 0 & 0.6 \\
\hline F185/3 & Beige & 30.5 & 18.2 & 34.7 & 1.2 & 2.36 & 0.47 & 0.67 & 1.86 & 0 & 2.92 & 0.69 & 0.48 & 0.43 & 3.35 & 1.25 & 0.92 \\
\hline F185/4 & Beige & 30.9 & 18.1 & 34.6 & 1.17 & 2.35 & 0.43 & 0.69 & 1.79 & 0 & 2.94 & 0.81 & 0.4 & 0.49 & 3.3 & 1.26 & 0.7 \\
\hline F185/5 & $\begin{array}{l}\text { Bluish- } \\
\text { black }\end{array}$ & 31.2 & 19.5 & 32.8 & 1.2 & 2.58 & 0.4 & 0.71 & 1.6 & 0.28 & 3.72 & 0.3 & 0.2 & 0 & 3.28 & 1.55 & 0.68 \\
\hline F185/6 & $\begin{array}{l}\text { Bluish- } \\
\text { black }\end{array}$ & 31.1 & 19.4 & 32.9 & 1.3 & 2.64 & 0.38 & 0.69 & 1.54 & 0.23 & 3.65 & 0.4 & 0.3 & 0 & 3.3 & 1.45 & 0.65 \\
\hline F185/7 & Blank & 37.4 & 23.2 & 34.4 & 0 & 0.81 & 0.24 & 0.26 & 0.46 & 0.04 & 1.46 & 0.28 & 0.2 & 0 & 0.85 & 0 & 0.4 \\
\hline F185/8 & Blank & 38.7 & 22.1 & 33.6 & 0 & 0.6 & 0.27 & 0.35 & 0.65 & 0.08 & 1.32 & 0.55 & 0.5 & 0 & 0.76 & 0 & 0.52 \\
\hline F185/9 & Beige & 31.3 & 17.1 & 33.1 & 1.4 & 2.66 & 0.62 & 0.72 & 1.79 & 0.47 & 2.53 & 0.75 & 0.67 & 0.4 & 4.33 & 1.32 & 0.84 \\
\hline F182/1 & Beige & 29.4 & 19.3 & 37 & 1.3 & 1.8 & 0.37 & 0.98 & 1.85 & 0 & 2.15 & 0.41 & 0.56 & 0 & 3.14 & 0 & 1.72 \\
\hline F182/2 & Yellow & 29.9 & 18 & 35.4 & 1.2 & 1.9 & 0.32 & 1.52 & 2.03 & 0 & 3.12 & 0.46 & 1.23 & 0.2 & 3.4 & 0 & 1.3 \\
\hline F182/3 & $\begin{array}{l}\text { Bluish- } \\
\text { black }\end{array}$ & 31.2 & 19.1 & 36.7 & 1.04 & 1.74 & 0.6 & 1.02 & 1.37 & 0.3 & 2.02 & 0.39 & 0.4 & 0 & 3.21 & 0.42 & 0.43 \\
\hline F182/4 & $\begin{array}{l}\text { Light } \\
\text { green }\end{array}$ & 29.9 & 18.0 & 36.4 & 1 & 1.9 & 0.4 & 0.58 & 2.03 & 0.5 & 3.1 & 0.46 & 0.72 & 0 & 3.4 & 1.2 & 0.36 \\
\hline F182/5 & $\begin{array}{c}\text { Coppery } \\
\text { red }\end{array}$ & 28 & 19 & 38.1 & 0 & 1.31 & 0.32 & 1.62 & 2.4 & 0.3 & 3.34 & 0 & 1.23 & 0.2 & 3.1 & 0.34 & 0.72 \\
\hline
\end{tabular}

\subsection{Deterioration phenomena}

The macroscopic and microscopic results revealed that F185 suffers from extensive deterioration, such as tears and missing parts (Figure 7a), fragility and disintegration (Figure 7b), dust and soiling matters (Figure 7d, e, f), flattening between glass boards (Figure $7 \mathrm{~g}$ ), and white fogging (Figure $7 \mathrm{~h}$ ). These deterioration phenomena are linked to the ill-adapted museum environment and the past

35 Amin, The documentation and treatment of a Coptic child's tunic in Egypt, 2019.

Abdel-Kareem, and El-Nagar, Non-destructive methods to investigate the deterioration, 2005.

Trojanowicz, et al, Chromatographic investigation of dyes extracted from Coptic textiles, 2004.

36 Abdel-Kareem, and El-Nagar, Non-destructive methods to investigate the deterioration, 2005.

Trojanowicz, et al, Chromatographic investigation of dyes extracted from Coptic textiles, 2004. 
conservation treatment with the fragment, ${ }^{37}$ especially those entailing consolidation with an ancient adhesive and storage by locking it between two glass boards. It is well-known that textile objects might be kept behind glass, but without mutual contact. These inappropriate procedures caused continual pressures on the object, blocked all ventilation, formed a little white fog upon the glass due to the released materials from the object, and the materials used in its treatment, caused the thermal degradation of fibers, etc. When keeping objects behind glass, a step-shaped rebate should ensure that no part of the object touches the glass. ${ }^{38}$

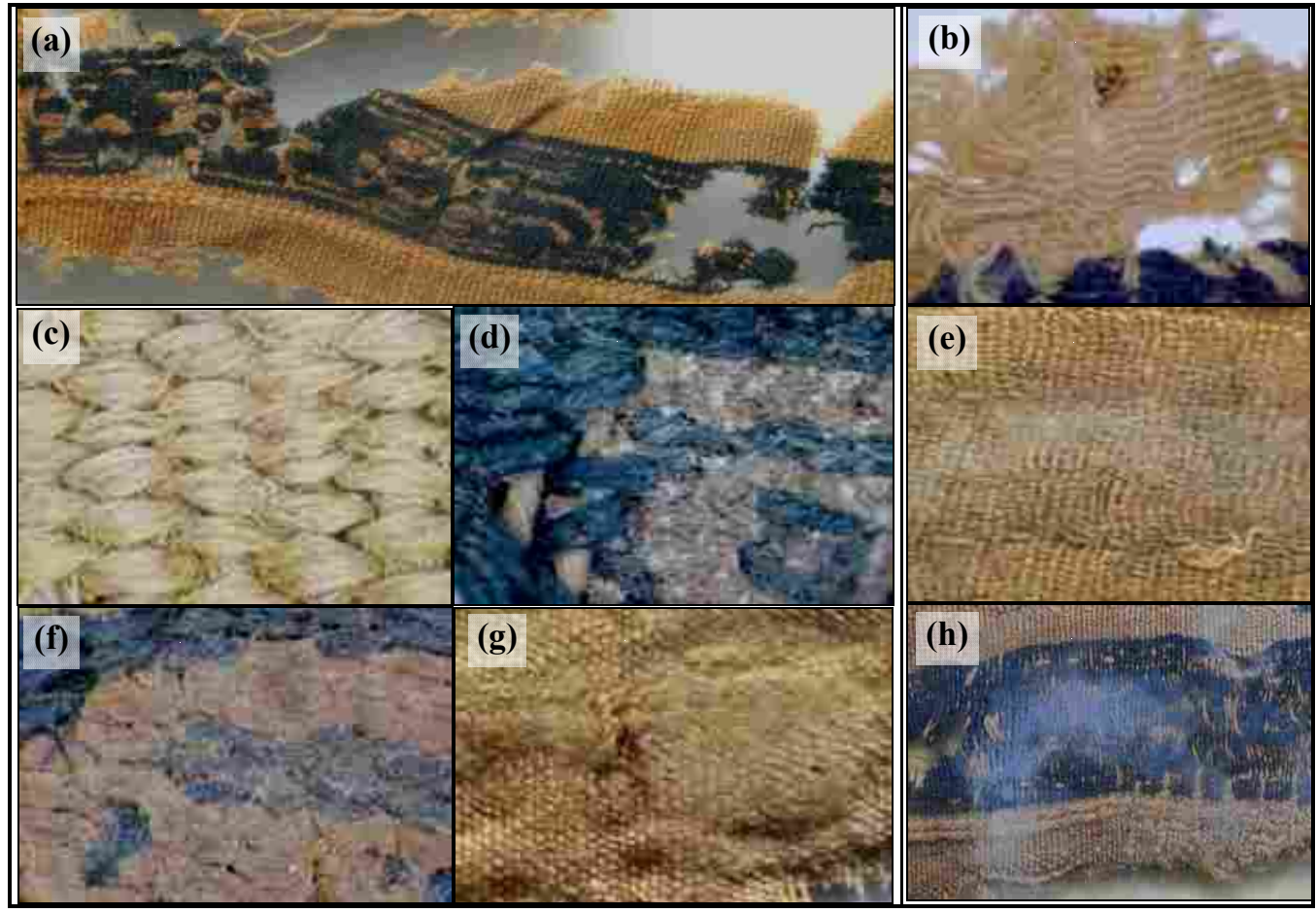

Fig. 7, deterioration phenomena, a Tears and missing parts. b Fragility and disintegration. $\mathbf{c}$ The tapestry plain weave structure $1 / 1$. d, e, f Dust and soiling matters. $\mathbf{g}$ Flattening between glass boards. $\mathbf{h}$ white fogging

Similarly, to the first fragment, F182 is tightly locked up between two glass boards. It suffers from extensive deterioration, such as fog upon the glass (Figure 1c), accumulated dust (Figure 8a, b), damage and color fading (Figure 8c), dirt oily and unknown stains (Figure 8d, e), remains of previous adhesives treatment (Figure 8f). All deterioration phenomena correspond to the exposure to light, fluctuations of temperature and humidity, and poor preservation conditions of the fragments. ${ }^{39}$

37 Elsayed, Conservation of The Flowers Canvas Painting, 2019.

Elsayed, Identification of the painting materials of a unique easel painting, 2019.

38 Tímár-Balázsy, and Eastop, Chemical principles of textile conservation,1998.

Landi, The textile conservator's manual, 1998.

Elsayed, Conservation of A Historic Panel oil-painting coated with an ancient varnish, 2019.

39 Uring, et al, The Bayeux embroidery: a dust deposition assessment, 2018.

Confortin, study of the photo-fading of an early synthetic dye in aqueous solution, 2010.

- 291 - Investigation and Analysis of Two Coptic Textile Fragments in Egypt 


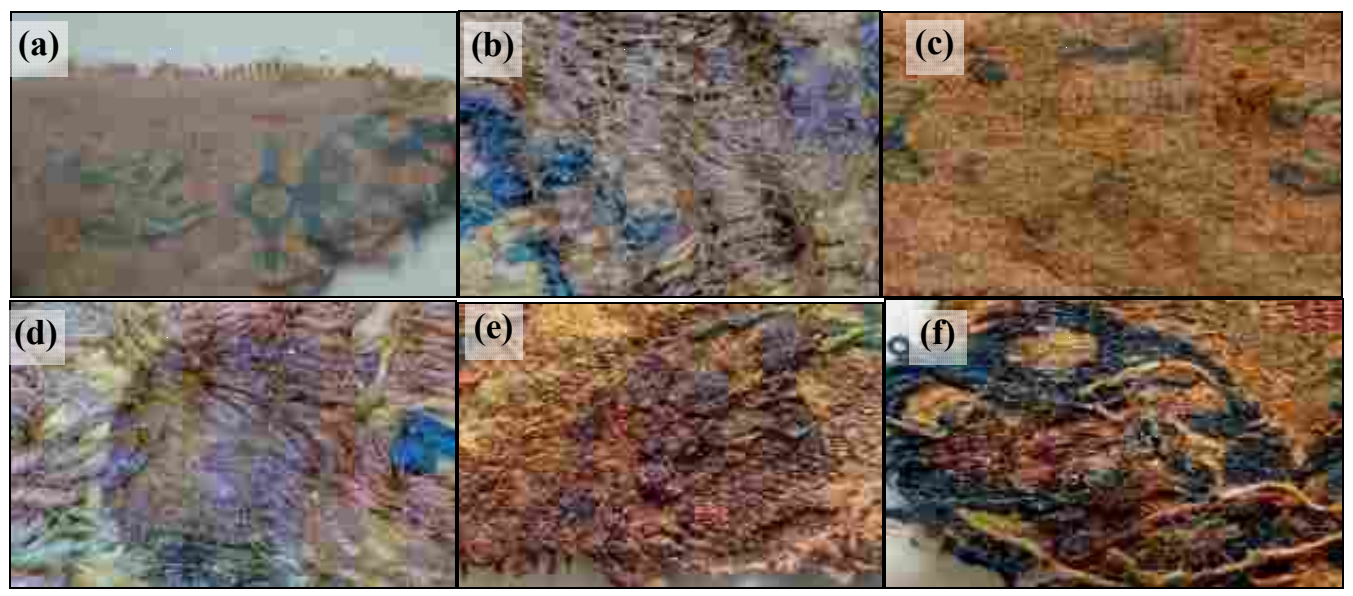

Fig. 8, Examples of deterioration phenomena in F182. a, b accumulated dust. c Brittleness and color fading. d, e dirt oily and unknown stains. f old adhesives.

The SEM micrographs of both fragments (Figure $4 \mathrm{~b}, \mathrm{f}$ ) revealed that the fibers are very damaged and covered with various amounts of accumulated dust, old adhesives, and stains. The more degraded and disintegrated observed fibers by SEM, the more deteriorative agents affected the object, especially temperature, humidity, and probably ancient anthropic use of the object. The more non-fibrous observed matters, the more pollutants, and soiling materials occurred in the ill-adapted environment of the object. SEM is commonly used to identify the types of fibers, and their morphological features of deterioration. These features of deterioration were extensive in some fibers to be identified by SEM. ${ }^{40}$

The analytical results of FTIR-ATR spectroscopy applied to the selected microsamples of F185 (figure 5) and F182 (figure 6) revealed the presence of-SO3- cysteic acid. at $\sim 1044 \mathrm{~cm}^{-1} .{ }^{41}$ Due to the aging factors affecting the fragments, and according to the reference sound wool, the intensities of different peaks changed as follows; amide I ( $\sim 1652 \mathrm{~cm})$ and amide II $(\sim 1544 \mathrm{~cm}-1)$ are noticeably decreased. The peak of amide III $\left(\sim 1235 \mathrm{~cm}^{-1}\right)$ is noticeably broadened, and the peak of cysteic acid $(\sim 1044$ $\left.\mathrm{cm}^{-1}\right)$ is increased. Cystine conversion into oxidation products such as cysteic acid in wool has been commonly identified by FTIR. These deterioration phenomena are corresponding to the physico-chemical factors, and probably the anthropic use of the objects. The cysteic acid signal usually increases with the increase of exposure time to aging factors, namely light. ${ }^{42}$ Moreover, $\mathrm{Na}, \mathrm{Mg}, \mathrm{Si}, \mathrm{P}, \mathrm{Ca}$, and possibly $\mathrm{Al}, \mathrm{Cl}, \mathrm{K}$, elements obtained by EDX might all correspond to soiling matters, resulting from the archaeological sites, where the fragments would have come from, or from the ill-

40 Alexiou, et al., In From the burial to the textile conservation lab, 2015.

Otłowska,et al Chromatographic and Spectroscopic Identification and Recognition of Natural Dyes, 2018.

41 Hofmann-de Keijzer et al., Dyes, dyeing techniques and dyestuff analysis, 2007.

Odlyha and Theodorakopoulos, Studies on woolen threads from historical tapestries, 2007.

42 Carr, and Lewis, An FTIR spectroscopic study of the photodegradation and thermal, 1993.

Odlyha and Theodorakopoulos, Studies on woolen threads from historical tapestries, 2007. 
adapted museum environment, where the fragments were displayed before locking up between glass panels. ${ }^{43}$

The adhesive material, adhering to the wool textile substrate, had to be analyzed separately (sample no. F182/6), as it was impossible to identify it in combination with wool fibers, being both proteinaceous materials ${ }^{44}$. The obtained spectrum (figure 9) of sample no. F182/6, which was delicately scratched by a scalpel from an adhesive spot, can be assigned to a protein-based adhesive, due to the characteristic signals of the amide carbonyl group ( $-\mathrm{CO}-\mathrm{NH}-)$. The $\mathrm{N}-\mathrm{H}$ stretching vibration was identified by the peak at $\sim 3400 \mathrm{~cm}^{-1}$; the stretching of the carbonyl group $(\mathrm{C}=\mathrm{O})$ and amide II (NH2) were confirmed by the peak at $\sim 1640 \mathrm{~cm}^{-1}$. While the peaks at $\sim 2850$ and $\sim 2925 \mathrm{~cm}^{-1}$ are due to the methylene group, the broad peak at $\sim 3000-3700 \mathrm{~cm}^{-1}$ can be assigned to hydroxyl and amide groups. The field observation by the naked eye, combined with these chemical results, shows that this corresponds to animal glue. It was common to use animal glue in mending archaeological crafts in the past, and it is known that the heritage artworks under study were treated by non-specialists a few decades ago. ${ }^{45}$

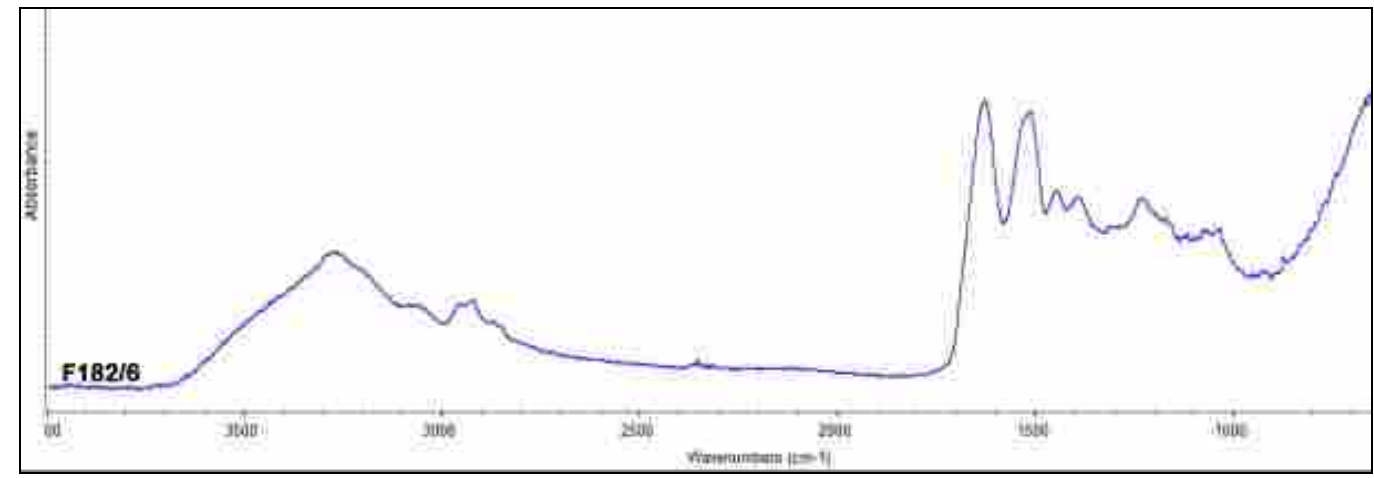

Fig. 9, The spectrum of sample no. F182/6 reveals the presence of animal glue.

\section{CONCLUSIONS}

The adopted investigation and analytical techniques revealed data about the two case-study fragments. SEM and FTIR-ATR were used to identify the fibers, and to distinguish the cellulosic (linen or cotton) from the proteinaceous ones (wool or silk). The techniques provided complementary and consistent results, physically and chemically confirming the types of fibers (sheep wool and linen).

Wool and linen were identified in F185, while F182 is completely made of wool. HPLC-DAD-MS was adequate for identifying natural dyes, thanks to the chromatographic separation and high efficiency of the MS and DAD detectors

43 Abdel-Kareem, and El-Nagar, Non-destructive methods to investigate the deterioration, 2005.

Trojanowicz, et al, Chromatographic investigation of dyes extracted from Coptic textiles, 2004. 44 Solazzo, Characterizing historical textiles and clothing with proteomics, 2019.

45 Zorba, Technique and palette of XIIIth century painting, 2006.

Rao, Proteomic identification of adhesive on a bone sculpture-inlaid wooden artifact, 2015.

Carr, and Lewis, An FTIR spectroscopic study of the photodegradation and thermal, 1993.

Kralov á nszky, Problems of the second restoration of two general 'satillas, 2009.

- 293 - Investigation and Analysis of Two Coptic Textile Fragments in Egypt 
coupled with the HPLC. In both fragments, natural indigo and weld were confirmed in the beige and bluish-black shades, respectively. In F182, weld and indigo were confirmed in mixture in the light green shades, weld and madder were confirmed in a mixture in the yellow shades, while madder was confirmed in the coppery red shades. In both fragments, the mordants were only suggested by the EDXS analysis, but not positively verified.

Detailed physical observation provided the archaeological and historical description, the decorative elements used, and the probable origin and use of both fragments, leading to dating the first fragment to the $2^{\text {nd }}-3^{\text {rd }}$ century $A D$, and the second fragment to the $5^{\text {th }}-6^{\text {th }}$ centuries AD. Detailed chemical results showed the degradation of both fragments, thus, it is recommended that both fragments be treated.

\section{ACKNOWLEDGMENTS}

The author acknowledge the assistance of lab facilities provided by the Research Infrastructures NanoEnviCz (Project No. LM2018124) supported by the Ministry of Education, Youth and Sports of the Czech Republic and the project Pro-NanoEnviCz (Reg. No. CZ.02.1.01/0.0/0.0/16_013/0001821) supported by the Ministry of Education, Youth and Sports of the Czech Republic and the European Union - European Structural and Investments Funds in the frame of Operational Programme Research Development and Education. 


\section{REFERENCES}

1 Abdel-Kareem (Omar), "Identification of dyestuffs in a rare Coptic garment using high performance liquid chromatography with photodiode array detection (HPLC-PDA)." Journal of Textile and Apparel, Technology and Management 6, 3 (2010) 1-7.

2 Abdel-Kareem, (Omar) and El-Nagar (Khaled), "Non-destructive methods to investigate the deterioration extent of Coptic Egyptian textiles." Journal of Textile and Apparel, Technology and Management 4, 4 (2005) 1-15.

3 Ahmed (Harby), Tahoun (Ibrahim), Elkholy (Ibrahim), Shehata (Adel), and Ziddan (Yassin), "Identification of natural dyes in rare Coptic textile using HPLC-DAD and mass spectroscopy in museum of Faculty of Arts, Alexandria University, Egypt." Dyes and Pigments 145 (2017) 486-492.

4 Alexander (Konstanta), Karydis (Christos) and Artemios (Oikonomou), "In From the burial to the textile conservation lab: the case of a late Roman charred textile from Katapola Amorgou." Textile, Archaeological Museum of Thessaloniki, 6 (2015) 31-37.

5 Amin (Enas), "The documentation and treatment of a Coptic child's tunic in Egypt." Egyptian Journal of Archaeological and Restoration Studies 9. 1 (2019) 1-11.

6 Bresee (Randal), "General effects of ageing on textiles" Journal of the American Institute for Conservation 25, 1 (1986) 39-48.

7 Carr (Christopher), Lewis (David), "An FTIR spectroscopic study of the photodegradation and thermal-degradation of wool." Journal of the Society of Dyers and Colourists 109, 1 (1993) 21-24.

8 Carroll (Diane), "Looms and textiles of the Copts: first millennium Egyptian textiles" in the Carl Austin Rietz Collection of the California Academy of Sciences, 1988.

9 Confortin (Daria), Neevel (Han), Brustolon (Marina), Franco (Lorenzo), Kettelarij (Albert), Williams (Renè) and van Bommel (Maarten), "Crystal violet: study of the photo-fading of an early synthetic dye in aqueous solution and on paper with HPLC-PDA, LC-MS and FORS." In Journal of Physics: Conference Series, vol. 231, no. 1, p. 012011. IOP Publishing, 2010.

10 Cooksey (Christopher), "Indigo: an annotated bibliography." Biotechnic \& Histochemistry 82, 2 (2007) 105-125.

11 Cooksey (Christopher), "Tyrian purple: 6, 6'-dibromoindigo and related compounds." Molecules 6, 9 (2001) 736-769.

12 Davis (Stephen), "Coptic Christology in practice Incarnation and divine participation in Late Antique and Medieval Egypt, Oxford University Press, 2008.

13 Elsayed (Yosr), "Conservation of a historic panel oil-painting coated with an ancient varnish layer." Shedet 6 (2019) 238-256.

14 Elsayed (Yosr), "Conservation of The Flowers Canvas Painting (1) at The Egyptian Agricultural Museum." Egyptian Journal of Archaeological and Restoration Studies 9, 1 (2019) 39-51.

15 Elsayed (Yosr), "Identification of the painting materials of a unique easel painting by Mahmoud Sa'id." Egyptian Journal of Archaeological and Restoration Studies 9, 2 (2019) 155-169.

16 Feller (Robert), " Accelerated aging, photochemical and thermal aspects, Getty Publications, 1995.

17 Garside (Paul), and Wyeth (Paul), "Identification of cellulosic fibres by FTIR spectroscopy differentiation of flax and hemp by polarized ATR FTIR." Studies in conservation 51, 3 (2006) 205-211.

18 Hofmann-de Keijzer (Regina), van Bommel (Maarten), Keijzer (de Matthijs), "Coptic textiles: Dyes, dyeing techniques and dyestuff analysis of two textile fragments of the MAK Vienna." In Methods of Dating Ancient Textiles of the 1st Millennium AD from Egypt and Neighbouring Countries, Lannoo Publishers: Antwerp, (2007) 214-228.

19 Jakes (Kathryn), Baldia (Christel), and Thompson (Amanda), "Infrared examination of fiber and particulate residues from archaeological textiles." In Archaeological Chemistry: Analytical Techniques and Archaeological Interpretation, Michael, D. G., Robert, J. Speakman, Rachel S. Popelka-Filcoff, Ed. ACS Publications: Washington (2007) 44-77.

- 295 - Investigation and Analysis of Two Coptic Textile Fragments in Egypt 
20 Kabbani (Raifah), "Conservation a collaboration between art and science, " The Chemical Educator 2, 1 (1997) 1-18.

21 Karydis (Christos), Oikonomou (Artemios), and Konstanta (Alexander), "The unpublished Coptic textiles of the monastery of St. John the theologian: preliminary results of previous alterations and scientific analysis" Mediterranean Archaeology \& Archaeometry, 19, 1 (2019) 133-142.

22 Kavkler (Katja), Gunde-Cimerman (Nina), Zalar (Polona), and Demšar (Andrej), "FTIR spectroscopy of biodegraded historical textiles." Polymer degradation and stability 96, 4 (2011) 574-580.

23 Kralov (nszky), "Problems of the second restoration of two general 'satillas (military coats) from 1848-1849." In Conserving textiles: studies in honour of Agnes Timar-Balazsy, Istvan, E.; Eastop, D.; Rockwell, C., Eds. Pulszky Hungarian Museum Association: ICCROM, Italy (2009) 97-102.

24 Landi (Sheila), The textile conservator's manual, Routledge (1998).

25 Lucas (Alfred), and Harris (John), "Ancient Egyptian materials and industries." Courier Corporation (2012).

26 Marouf (Mohamed), "Identification and Characterization of Fibers and Weave Structures of Three Archaeological Textiles Fragments, from Sohag Excavations, Egypt', Journal of International Environmental Application and Science 5, 5 (2010) 957-964.

27 Marouf (Mohamed), and Saber (Medhat), "Treatment and Conservation of Archaeological Garment from Greco-Roman Period-The Egyptian Museum." 4th International Congress on Science and Technology for the Safeguard of Cultural Heritage in the Mediterranean Basin, Cairo (2009) 510-521.

28 Marques (Rita), Sousa (Micaela), Oliveira (Maria), and Melo (Maria), "Characterization of weld (Reseda luteola L.) and spurge flax (Daphne gnidium L.) by high-performance liquid chromatography-diode array detection-mass spectrometry in Arraiolos historical textiles." Journal of chromatography A 1216, 9 (2009) 1395-1402

29 Michael (Vivian), "Revival of the Coptic Tapestry Decoration in Denim Fashion." International Journal of Costume and Fashion 16, 2 (2016) 81-99.

30 Michael (Vivian), "The Creativity in Decoration Designs with Coptic symbols', International Journal of Human Ecology 2011, 12 (1), 101-113.

31 Moiteiro (Cristina), Gaspar (Helena), Rodrigues (Ana), Lopes (João), and Carnide (Valdemar), "HPLC quantification of dye flavonoids in Reseda luteola L. from Portugal." Journal of separation science 31, 21 (2008) 3683-3687.

32 Mouri (Chika), Aali (Abolfazl), Zhang (Xian), and Laursen (Richard), "Analysis of dyes in textiles from the Chehrabad salt mine in Iran." Heritage Science 2, no. 1 (2014): 20.

33 Odlyha (Marianne), Theodorakopoulos (Charis), and Campana (Roberto), " Studies on woolen threads from historical tapestries." AUTEX Research Journal 7, 1 (2007) 9-18.

34 Ortega Saez (Natalia), Vanden Berghe (Ina), Schalm (Olivier), De Munck (Bert), and Caen (Joost). "Material analysis versus historical dye recipes: ingredients found in black dyed wool from five Belgian archives (1650-1850)." Conservar Património 31 (2019) 115-132.

35 Otłowska (Olga), Ślebioda (Marek), Kot-Wasik (Agata), Karczewski (Jakub), and ŚliwkaKaszyńska (Magdalena), "Chromatographic and Spectroscopic Identification and Recognition of Natural Dyes, Uncommon Dyestuff Components, and Mordants: Case Study of a 16th Century Carpet with Chintamani Motifs." Molecules 23, 2 (2018) 339.

36 Peggie (David), Hulme (Alison), McNab (Hamish) and Quye (Anita), "Towards the identification of characteristic minor components from textiles dyed with weld (Reseda luteola L.) and those dyed with Mexican cochineal (Dactylopius coccus Costa)" Microchimica Acta 162, 3-4 (2008) 371-380.

37 Pritchard (Frances), "Clothing culture: dress in Egypt in the first millennium AD: clothing from Egypt in the collection of the Whitworth Art Gallery." the University of Manchester, 2006.

38 Proniewicz (Leonard), Paluszkiewicz (Czesława), Wesełucha-Birczyńska (Aleksandra), Majcherczyk (Halina), Barański (Andrzej), and Konieczna (Anna), " FT-IR and FT-Raman 
study of hydrothermally degradated cellulose." Journal of Molecular Structure 596 1-( 2001) 163-169.

39 Rao (Huiyun), Yang (Yimin), Abuduresule (Idelisi), Li (Wenying), Hu (Xingjun), and Wang (Changsui), "Proteomic identification of adhesive on a bone sculpture-inlaid wooden artifact from the Xiaohe Cemetery, Xinjiang, China." Journal of Archaeological Science 53 (2015) 148-155.

40 Saltzman (Max), " Identifying dyes in textiles." American Scientist 1992, 80 (5), 474-481.

41 Saweros, (Ibrahim), "Thoughts on the Coptic Literature Heritage." SHEDET 2, no. 2 (2015): 176-180.

42 Saweros (Ibrahim), "Angels in Coptic tradition." SHEDET 66 (2019) 74-91.

43 Schaffer (Erika), "Fiber identification in ethnological textile artifacts." Studies in conservation 263 (1981) 119-129.

44 Schindler, (W) and Finnimore, (E), 'Chemical analysis of damage to textiles." Chemical Testing of Textiles (2005) 145-241.

45 Solazzo (Caroline), "Characterizing historical textiles and clothing with proteomics." Conservar Património 31 (2019) 97-114.

46 Thomas (Thelma), "Coptic and Byzantine textiles found in Egypt: Corpora, collections, and scholarly perspectives." in: Egypt in the Byzantine World, 300 - 700, UK, Bagnall, R. S., Ed. Cambridge University Press: UK, (2007) 137-162.

47 Thompson (Deborah), "Coptic textiles in the Brooklyn Museum." Brooklyn Museum, 1971.

48 Tímár-Balázsy (Ágnes), and Eastop (Dinah), "Chemical principles of textile conservation." Butterworth-Heineman, Oxford, UK (1998) .

49 Troalen (Lore), Phillips (Ashley), Peggie (David), Barran (Perdita), and Hulme (Alison), "Historical textile dyeing with Genista tinctoria L.: a comprehensive study by UPLC-MS/MS analysis." Analytical Methods 6, no. 22 (2014): 8915-8923.

50 Trojanowicz (Marek), Orska-Gawryś (Jowita), Surowiec (Izabella), Szostek (Bogdan), Urbaniak-Walczak (Katarzyna), Kehl (Jerzy), and Wróbel (Marek), "Chromatographic investigation of dyes extracted from Coptic textiles from the National Museum in Warsaw." Studies in conservation 49, 2 (2004) 115-130.

51 Uring (Pauline), Chabas (Anne), De Reyer (Dominique), Gentaz (Lucile), Triquet (Sylvain), Mirande-Bret (Cécile), and Alfaro (Stéphane), "The Bayeux embroidery: a dust deposition assessment" Heritage Science 6, 1 (2018) 23.

52 Van Strydonck (Mark), De Moor (Antoine), and Bénazeth (Dominique), "14 C Dating Compared to Art Historical Dating of Roman and Coptic Textiles from Egypt." Radiocarbon 46, 1 (2004) 231-244.

53 Van, (P. M.), Hooft, (T.), Raven, (M. J.), Van-Rooij, (E. H. C.); Vogelsang-Eastwood, (G. M.), "Pharaonic and early medieval Egyptian textiles." RIJKS Museum van Oudheden: Leide (1994).

54 Vogelsang-Eastwood (Gillian), Kolkman (Joost), " Embroidery from the Arab world." Primavera Press in coop with Textile Reasearch Centre." Leiden (2010).

55 Witkowski (Bartłomiej), Ganeczko (Monika), Hryszko (Helena), Stachurska (Monika), Gierczak (Tomasz), and Biesaga (Magdalena), "Identification of orcein and selected natural dyes in 14th and 15th century liturgical paraments with high-performance liquid chromatography coupled to the electrospray ionization tandem mass spectrometry (HPLCESI/MS/MS)." Microchemical Journal 133 (2017) 370-379.

56 Yoder (David), "The use of "soft" X-ray radiography in determining hidden construction characteristics in fiber sandals." Journal of Archaeological Science 35, 2 (2008) 316-321.

57 Yong-hua (Ren), Bian-xia (Liu), and Xiao-ning (Sun), "Research on the Aging of Natural Fiber Textiles." Advances in Biomedical Engineering 9, 1 (2012).

58 Zorba (T.), Pavlidou (E.), Stanojlovic (M.), Bikiaris (D.), Paraskevopoulos (K. M.;), Nikolic (V.), Nikolic (P. M.), "Technique and palette of XIIIth century painting in the monastery of Mileseva." Applied Physics a-Materials Science \& Processing 83, 4 (2006) 719-725. 